\title{
midiätica@e
}

\section{Lana Del Baile: videomemes musicais, ativismo de fãs e performances de gosto nos sites de redes sociais}

\author{
Lana Del Baile: musical videomemes, fan activism \\ and taste as performance in social network sites
}

Luana INOCÊNCIO ${ }^{1}$

\section{Resumo}

Ao compreender os memes de internet como artefatos da cultura digital, esta pesquisa investiga as articulações das camadas estéticas e performáticas dos videomemes que ressignificam produtos musicais por meio do humor em plataformas como o Facebook e YouTube. Interessa-nos questionar, especificamente, os videomemes enquanto mediadores da experiência, consumo e circulação musical, bem como as práticas de ativismo de fãs e performances de gosto protagonizadas. Utilizando como corpus os videomemes da canção High By The Beach, da cantora indie pop Lana Del Rey, vislumbra-se a hipótese de que deste fenômeno emerge uma cultura memética musical, vasta e carregada de peculiaridades, marcada por um repertório cultural de referências e imaginários em torno do qual atores sociais brasileiros reunidos em fandoms (sub)culturais performatizam gostos e consumos, se reconhecem, socializam e disputam.

Palavras-chave: Memes. Sites de redes sociais. Performance de gosto. Videomemes. Fandom.

\begin{abstract}
Understanding internet memes as artifacts of digital culture, this research investigates the articulations of the aesthetic and performance layers of videomemes that re-signify music products through humor on platforms such as Facebook and YouTube. Specifically, we are interested in questioning videomemes as mediators of experience, consumption and musical circulation, as well as the practices of fan activism and performances as taste carried out. Using as corpus the videomemes of the song High By The Beach, by indie pop singer Lana Del Rey, the hypothesis is that from this phenomenon emerges a musical memetic culture, vast and loaded with peculiarities, marked by a cultural repertoire of references and imaginaries around which Brazilian

\footnotetext{
1 Doutoranda em Comunicação pela Universidade Federal Fluminense (PPGCOM/UFF). Professora Substituta do Curso de Publicidade e Propaganda da Universidade Federal Fluminense. Pesquisadora do Laboratório de Pesquisa em Culturas Urbanas e Tecnologias da Comunicação (LabCult/UFF) e do Grupo de Pesquisa MORE THAN LOUD: Cenas musicais urbanas e culturas DIY (Universidade do Porto/Portugal). E-mail: luanahinocencio@hotmail.com
} 


\section{midiätica@s}

social actors meeting in (sub)cultural fandoms performatizes tastes and consumptions, recognizes themselves, socializes and contests.

Keywords: Memes. Social network sites. Taste as performance. Videomemes. Fandom.

\section{Introdução}

Em meados de 1990, longe dos museus e tradicionais ambiências de amplo desenvolvimento e circulação da arte, um tipo de expressão estética tomava os inóspitos fóruns de discussão na web. Originalmente emergindo como uma subcultura ${ }^{2}$ que marcava o início das interações sociais através do fluxo de conteúdo amador na rede, os memes se proliferaram nestas comunidades online baseadas na postagem de imagens e textos carregados de referências e pautados na ironia e humor.

Ao se estabelecerem como um fenômeno digital emergente no fecundo terreno cibercultural, pela inovação no formato, pela articulação dos signos, com alto poder de síntese (densos no conteúdo e simples no formato) e pelo exercício de transposição da comicidade (INOCÊNCIO, 2017), os memes de internet são criados a partir de desvios, recortes, releituras, apropriações e recriações livres de textos e obras audiovisuais. Assim, tal fenômeno operacionaliza uma série de epifanias e metáforas que servem de ignição para aguçar e instigar esta pesquisa.

Nesse contexto, na etapa de mapeamento das amostras de memes em formato de vídeo - aqui denominados videomemes - que derivassem de um mesmo videoclipe, foram consideradas variáveis a partir de tags de busca específicas ${ }^{3}$ em comunidades digitais abertas e fechadas dos sites de redes sociais Facebook e YouTube. Com grande

\footnotetext{
${ }^{2}$ No decorrer desta investigação, acionaremos a noção de que os traços de sociabilidade identificados em torno do consumo e produção de memes em sites de redes sociais são encontrados no conceito de subcultura, que de acordo com Amaral (2008) materializa-se como uma construção discursiva polissêmica, marcada pela fluidez, efemeridade e disputas de gosto e distinção de natureza estética em determinada comunidade em específico, estabelecidas no consumo midiático e fortemente vinculadas aos grupos de fãs.

${ }^{3}$ Foram utilizadas ferramentas de busca e extração de dados próprias de gerenciamento dos SRSs, centrando nas tags e interrelação entre estas, como "clipe", "High By The Beach", "LDR", "spoof", "paródia", "vazou", "Lana", assumindo-se as potencialidades de possuir um perfil membro de variadas comunidades digitais fechadas ou secretas de cultura pop e humor, como LDRV, Hold This Marimba, Please Come To Brazil e Pandlr; bem como pesquisa reversa de imagens que constituíam frames específicos de alguns GIFs manipulados para as montagens. A seleção de tais amostras para constituir o corpus deu-se por natureza quali-quantitativa, pelo volume de visualizações e reações em sincronia com os comentários dos interagentes.
} 


\section{midiäticales}

quantidade de variações meméticas, a música High By The Beach, da cantora e compositora americana de indie pop Lana Del Rey, que possui um grande fandom brasileiro, organizado em comunidades como o grupo LDRV (Lana Del Rey Vevo) ${ }^{4}$. O videoclipe oficial da canção foi lançado em 13 de agosto de 2015 em seu canal do Vevo no YouTube, três dias após a divulgação do single e marcando a estreia do seu quarto álbum de estúdio, Honeymoon. Atualmente com quase 100 milhões de visualizações, o vídeo rendeu diversas apropriações em formato de meme, postadas em páginas e perfis do Facebook e YouTube, aqui analisadas.

Deste modo, as amostras trazidas se inserem como práticas de ativismo de fãs derivativas de formas de fanvideo, que desafiam certa soberania hegemônica do sistema de estratégias de popularização da indústria do entretenimento. A repetição de alguns destes elementos, em versões bastante aproximadas com as do vídeo original, revelam afinidade técnica nas execuções por parte dos produtores amadores, em sua produção, edição e montagem, bem como um olhar atento à reprodução da performance, como observaremos.

\section{Performances de gosto e produções do ativismo de fãs na cultura pop}

Ao longo do último século, práticas independentes de desmontagem, redesenho e colagem de materiais impressos, sonoros e visuais começaram a se popularizar, a exemplo dos zines gráficos e mashups musicais, rearranjando imagens, sons e textos. Com a popularização e barateamento dos computadores, além da miniaturização de dispositivos de captação de imagem e som, programas de edição cada vez mais user friendly e amplamente intuitivos, os meios de comunicação passaram a sofrer progressivos deslocamentos e integrações. Novos modos de edição audiovisual são disseminados e incorporados culturalmente ao consumo midiático, difundindo a prática remix (MANOVICH, 2001).

Santaella (2008) lembra que a cultura remix empresta seus procedimentos de muitos movimentos próprios do modernismo e pós-modernismo: apropriação, colagem, dadaísmo, grafite, fotomontagem e pop art. Mas os reais precedentes da remixabilidade

\footnotetext{
${ }^{4}$ Grupo secreto, criado inicialmente para reunir apenas os fãs mais "fervorosos" da artista e de outras expoentes do gênero indie, como Lorde, Florence Welch, Grimes e Björk, depois abrindo para que membros pudessem adicionar outros, ainda que estas solicitações externas fossem mediante verificação atenta dos seus perfis.
} 


\section{midiätica@e}

encontram-se na música eletrônica, para a qual, desde os anos 1980, o remix tornou-se o método-chave, através do equipamento de sampler, que sintetiza e armazena sons, permitindo aos DJs reproduzirem diferentes efeitos, sampleando e fazendo mashups de músicas já existentes.

Montagens de GIFs com imagens em movimento cíclico com trechos de filmes, telenovelas e videoclipes recheiam os sites de redes sociais diariamente, possibilitando aos interagentes intervenções para ressignificar tais produtos audiovisuais. É, inclusive, cada vez mais comum remixes e mashups musicais criados por fãs, bem como fanfictions ${ }^{5}$ elaboradas por leitores, fazerem tanto sucesso quanto os seus produtos cânones. $\mathrm{Na}$ estética da remixabilidade, essas práticas passam a influenciar o modo como os atores sociais recombinam os elementos de sua cultura, mesclando linguagens, sentidos e identidades.

Na possibilidade desses desvios, recortes, releituras, de apropriação e criação livre, os elementos de diversas culturas antes separados, passaram a coexistir imersos e carregados de simbolismos da cultura pop, como trechos de um vídeo viral disseminado nas próprias plataformas ciberculturais, por exemplo, ou ainda, trechos de formatos midiáticos do entretenimento tradicional, como seriados, filmes, videoclipes, desenhos animados, etc.

Nessa remixabilidade colaborativa, os participantes realizam curadoria coletiva de conteúdo, extraem informações dos mais diversos tipos - sonoras, visuais, verbais absorvendo-as no seu próprio espaço, remisturando-os, disponibilizando-as para os outros. Grandes exemplos dessas apropriações criativas enquanto experiências estéticas na web (CAMPANELLI, 2010) pelos fãs são as fanarts, produções criadas por fãs para homenagear ou satirizar seus produtos de entretenimento favoritos, como séries, filmes, livros, animações, a partir de filmes caseiros, narrativas ficcionais que desdobram as obras originais, legendagem, paródias, desenhos, pinturas.

Nesse contexto, Amaral, Souza e Monteiro (2015) analisam as diversas formas de produções de fandoms, tais como fanfics, fanzines e os fanvideos que se corporificam nos videomemes musicais aqui estudados, enquanto práticas de ativismo de fãs, dentre outras ações mais relacionadas a mobilizações coletivas para causas sociais e cívicas. Ao mapear tais práticas, as autoras retomam algumas questões problematizadas por

\footnotetext{
${ }^{5}$ Ficções escritas por fãs baseando-se nas obras originais.
} 


\title{
midiätica@e
}

Bennet (2012) e Brough e Shresthova (2012), que pontuam o ativismo de fãs enquanto uma ação permeada de intencionalidade contra a soberania hegemônica dos modos de produção das grandes indústrias do entretenimento e seu sistema, como um modo de engajamento político, social e cultural, ainda que pelo viés das rupturas e desconstruções.

Pautados fundamentalmente pelas práticas colaborativas de apropriação de produtos do entretenimento, estes fãs realizam modos de resistência criativa, ao propor usos alternativos às definições pré-estabelecidas pela indústria de bens culturais em seus produtos e serviços, reescrevendo e reeditando suas narrativas, como uma ressignificação da experiência do consumo.

Ao tangenciar alguns aspectos relacionados às formas de apropriação cultural, Fiske (1989) observa a paródia em específico como um tipo de repertório popular, por meio do qual o público transforma produtos em matéria-prima para suas próprias interações sociais. Segundo o autor, esse tipo específico de comicidade mescla os apelos risíveis do humor a uma referência específica compartilhada por determinado grupo, sendo, assim, precisamente o que a torna tão sui generis, uma vez que pode expressar experiências compartilhadas, em que é necessário que os "piadistas" e o seu público apreendam determinados repertórios em comum, como pontuam Jenkins, Ford e Green (2015, p.258):

\begin{abstract}
As referências específicas em termos culturais [...] proporcionam prazer ao público que gosta de criar links entre diferentes textos e reconhece quando os textos fazem referência entre si. [...] Quando os membros do público escolhem retransmitir textos de mídia, eles demonstram que pertencem a uma comunidade, que estão in em relação à referência e compartilham alguma experiência em comum.
\end{abstract}

Assim, reconhecer determinada referência define alguém como insider quanto a algum produto do entretenimento, constituindo-o como verdadeiro membro de sua comunidade de fãs, ao tempo em que desvia outsiders - aqueles que não se enquadram naquela ambiência que gira em torno de certos repertórios - para quem este não agrega valor algum.

Ao debater sobre essa relação de auto etiquetamento implícita nas relações experienciais entre os interagentes e as materialidades das tecnologias nos sites de redes sociais, Amaral (2014) caracteriza a noção da performance de gosto, que perpassa as 


\section{midiätica@e}

questões de identidade e seus modos de estetização do eu. A autora enfatiza a cultura pop enquanto vetor que aglutina e possibilita a propagabilidade de variadas produções vinculadas à cultura dos fãs - como os memes - e suas preferências nos sites de redes sociais. Nesta proposição, a noção de performance de gosto

visa restabelecer a natureza performativa da atividade do gosto, em vez de torna-la meramente um hábito. Quando alguém diz que ama opera ou rock - e o que alguém gosta, como e porque gosta - já é uma maneira de gostar mais desse gênero do que de outro. Música é um evento e uma ocorrência, o que significa que ela é perpetuamente transformada por qualquer contato com o seu próprio público, do qual ela inevitavelmente depende. Gostar não significa aprovar a identidade social de alguém, rotulando alguém para caber em um único papel, observar um rito ou passivamente ler as propriedades "contidas" em um produto como as melhores. O gosto é uma performance: ele atua, engaja, transforma e é sentido (HENNION, 2005, p. 133 apud AMARAL, 2014, p. 3).

Orientadas pela cultura midiática, essas práticas em busca de um senso de pertencimento estão diretamente relacionadas à construção de sentido, trocas de capitais simbólicos e distinções sociais de que trata Bourdieu (2007). O autor afirma que o gosto é mutuamente um fator determinante para os processos identitários dos sujeitos, posto que o gosto classifica o próprio classificador (AMARAL, 2014, p.448), havendo assim uma "determinação socioeconômica circunstancial refletida em diferentes níveis econômicos e no capital cultural nos quais residem relações sociais de pertencimento e exclusão embutidas no ato de classificar um gosto como inferior ou superior". Nesse contexto, performances de gosto nas redes digitais originadas a partir dos fãs carregam, assim, tanto o DNA dos produtos midiáticos dos quais se originaram quanto os processos identitários sociais e culturais dos interagentes que os compartilham, posto que são pedaços de um discurso público comentando eventos/produtos/tensões da cultura pop midiática, como observaremos na análise mais à frente.

\section{Memes, videomemes e apropriação midiática}

Um atributo central dos memes de internet é a produção de diferentes versões a partir de um objeto inicial, versões estas que são criadas pelos interagentes e articuladas como paródias, remixes ou mashups. Estruturadas com interfaces cognitivas flexíveis, plásticas e adaptáveis, algumas plataformas multimidiáticas, como sites de redes sociais 


\section{midiäticales}

específicos, contribuem para o processo criativo (SHIFMAN, 2013) pautado na instantaneidade e característico da cultura participativa, revelando novas possibilidades de produção de sentido e memória coletiva na rede.

Com tais bases, os memes digitais são manifestações latentes de uma subcultura que originalmente marcou o início das interações sociais na web, através do fluxo de conteúdo na rede em sites de imageboards, fóruns de discussão que se baseiam na postagem de imagens e texto (também chamados de chans), cujo exemplo mais expressivo é o $4 \operatorname{chan}^{6}$. Inicialmente um ambiente bastante povoado por gamers online no intervalo de suas atividades, os chans eram considerados pelos próprios frequentadores como parte do lado mais obscuro da web, cujo formato e dinâmica favoreceram o surgimento de vários memes da internet, como é o caso do Trollface, do Philosoraptor e do Pedobear.

É importante observar que muitos destes interagentes que circulam memes são em sua maioria early adopters ${ }^{7}$ de sites de redes sociais, sempre atentos às tendências destas redes, como novas funcionalidades e alterações em seus algoritmos com relação, por exemplo, a qual tipo de publicação possibilita maior alcance, entre vídeos, GIFs, imagem estática ou apenas texto. Muitos destes estão inseridos também em grupos específicos para troca de memes que relacionam as notícias e acontecimentos do cotidiano a trechos de produtos da cultura pop, além de assinarem as notificações de páginas de Facebook que os circulam, sendo os primeiros a recebê-los em seu feed. São, enfim, participantes intensamente familiarizados com as aplicabilidades das plataformas, com um grande nicho de perfis conectados a eles, tanto para receber estas montagens quanto para postá-las e tê-las rapidamente e em grande número compartilhadas.

Nas comunidades online de maior circulação deste tipo de conteúdo, verifica-se o uso dos memes como uma forma de capital social, separando aqueles que estão em maior contato com os variados formatos meméticos dos menos familiarizados. Diferentes gêneros de meme envolvem diferentes níveis de habilidades cognitivas, uma

\footnotetext{
${ }^{6}$ Disponível em: < http://www.4chan.org/>. Acesso em: 05 ago. 2018.

${ }^{7}$ No contexto do consumo de sites de redes sociais, early adopters é o termo geralmente aplicado aos primeiros atores que adotam determinados sites de redes sociais antes de sua popularização. São acostumados a aderir e experimentar antecipadamente inovações tecnológicas, como sites, softwares e gadgets, e outras tendências, como estilos de vida, moda, hobbies, linguagens, etc.
} 


\section{midiätica@e}

vez que alguns podem ser entendidos (e criados) pela maioria das pessoas, enquanto outros exigem conhecimento detalhado sobre uma subcultura memética específica, havendo a diferenciação entre aqueles que estão "por dentro" e são, portanto, parte da comunidade e aqueles que são outsiders.

Relacionando esse debate aplicado às culturas de fãs e ao debate público, Milner (2016) traz importantes contribuições para os estudos dos memes digitais ao analisar como processos, identidades e políticas se entrelaçam nos discursos dos memes. Para o autor, ao inserir-se em subculturas meméticas, é demandado aos interagentes a apreensão de certos repertórios, ou letramentos (também chamados de literacias). Assim, para criar variações meméticas inovadoras e realmente cômicas contextualizadas a determinado tema que é debatido naquela comunidade digital, é essencial compreender os processos que os orientam, como fluência no reconhecimento de referências culturais e ter competências cognitivas (letramento). Uma vez proficientes nesses processos, os interagentes poderiam de fato contribuir de forma mais transformadora, constituindo parte de um público plural e diverso, com disputas representacionais e amplas visões culturais sobre um mesmo debate.

Observa-se que há uma emergente e progressiva atividade de interagentes reunidos em comunidades cuja prerrogativa principal é a circulação de memes, seja através de sites específicos de cultura digital ou de páginas do Facebook, Tumblr, Twitter, ou ainda fóruns de imageboards como o 9Gag, que trazem os memes como forma de expressão cultural e comunicação para o espaço digital. Tais ambientes ampliam as possibilidades do estudo de comunidades online, pois constituem um campo de interação, registro de dados e vasto material multimídia, o que facilita a coleta de dados e proporciona uma análise mais aprofundada e minuciosa das amostras.

Nesta pesquisa, como etapa fundamental de aproximação empírica da natureza do objeto compreendido na análise, os videomemes musicais, foi realizada uma etapa taxonômica inicial - a ser desdobrada em trabalhos futuros. Foram identificados, a priori, quatro modalidades de videomemes fanmades: 1) recut trailer; 2) video fad; 3) lipsynch; 4) e spoof. O recut trailer (ou retrailer) é um trailer "fake", baseado em imagens de outros trailers, filmes, animações e outros produtos midiáticos audiovisuais - em muitos casos, até fazendo crossovers de universos ficcionais ou gêneros fílmicos 


\section{midiătica@e}

diferentes - com produções que criam um tipo de fanfiction fílmica anunciando supostos lançamentos cinematográficos, como Thundercats ${ }^{8}$.

Outro exemplo expressivo de videomeme é o video fad, no qual um ou mais participantes performatizam uma mesma dança ou encenam uma mesma posição específica, como o famoso Harlem Shake ${ }^{9}$, que hitou em 2014. Já os lip synch, ou $l i p d u b$, são videoclipes em que um indivíduo ou grupo combina seus movimentos labiais a uma música (SHIFMAN, 2013), redublando-a, como o caso de Numa Numa Dance $^{10}$. O chamado spoof, ou vídeo-paródia, é o formato de videomemes mais comum encontrado espalhado pelos sites de redes sociais, como as paródias da clássica cena do filme A Queda! - Os Últimos Dias de Hitler, em que uma busca no YouTube revela a existência de mais de 150 mil versões hospedadas ${ }^{11}$, nas quais o füher se enfurece com diferentes assuntos, como a final da Copa 2014, com os mistérios não revelados do seriado Lost, com nomes conhecidos da política, do esporte e da música.

Há ainda uma categoria de videomemes spoof que ilustra com maior amplitude o fenômeno da imitação de narrativas audiovisuais, que são as paródias de videoclipes musicais disseminadas principalmente no Facebook e YouTube, cujos exemplos exploraremos mais detalhadamente, buscando compreender as relações entre som e imagem que tornam este tipo de gênero de memes de internet o mais complexo e revelador do comportamento de apropriação amadora.

\section{Dos videoclipes pós-MTV aos fanvideos}

Diversas plataformas, ou artefatos midiáticos, protagonizam um papel especial como mediadores da experiência cultural desses interagentes nas redes digitais, como é o caso do YouTube, especialmente valioso para o corpus específico deste trabalho videomemes musicais. Pereira de Sá (2014) caracteriza o este site como mediador da experiência musical nas redes digitais e circulador dos denominados videoclipes pós-

\footnotetext{
${ }^{8}$ Vídeo disponível em: <https://www.Youtube.com/watch?v=fb50GMmY5nk>. Acesso em: 05 ago. 2018.

9 Vídeo disponível em: <https://www.Youtube.com/watch?v=8vJiSSAMNWw>. Acesso em: 05 ago. 2018.

${ }^{10}$ Vídeo disponível em: <https://goo.gl/XFbgja>. Acesso em: 05 ago. 2018.

${ }^{11}$ Vídeo disponível em: 〈https https://goo.gl/Y846LT>. Acesso em: 05 ago. 2018.

Ano XI, n. 21 - jul-dez/2018 - ISSN 1983-5930 - http://periodicos.ufpb.br/ojs2/index.php/cm
} 


\section{midiätica@e}

MTV, destacando-se como plataforma que inaugura novas dimensões estéticas, lúdicas e de sociabilidade, a partir de suas potencialidades tecnológicas em conjunto com práticas culturais: "a rede de mediadores que transformou o YouTube num sistema cultural é ampla, complexa e heterogênea, indo além da dicotomia entre usuários comuns (amadores) versus profissionais" (PEREIRA DE SÁ, 2014, p.161).

Nesse cenário, ambientados nas plataformas YouTube e Facebook, os videomemes apresentam uma linguagem marcada pela noção de paródia, reapropriação de narrativas audiovisuais e performance. Estas reinterpretações se dão através da intervenção individual ou coletiva sobre um vídeo original, que pode ser parodiado, reeditado e ressignificado.

Materializadas em reedições, relegendagem, redublagem, mashups e colagens de elementos de áudio e vídeo associados ao amadorismo ${ }^{12}$, essas criações são valorizadas como "vídeos de YouTube", um produto orgânico e genuíno da cultura participativa, em que "elementos tais como humor, espontaneidade, improviso e nonsense tornaram-se marcas estéticas importantes para circulação de vídeos musicais" (PEREIRA DE SÁ, 2014, p.164).

Os videomemes musicais, recorte sobre o qual nos debruçaremos ao longo desta investigação, ilustram com maior amplitude o fenômeno da imitação de narrativas audiovisuais, que são as paródias de videoclipes e apresentações musicais disseminadas principalmente no YouTube e Facebook, também chamadas de spoofs, cujos exemplos exploraremos mais detalhadamente, buscando compreender as relações entre som e imagem que tornam este tipo de gênero memético o mais complexo e mais revelador do comportamento de apropriação amadora por parte dos interagentes.

Pertencentes à categoria de produções fanmade denominada vidding, fanvideo ou fanvid, os videomemes investigados nesta pesquisa constituem-se de edições e colagens de elementos de áudio e vídeo musicais com insumos de outros produtos midiáticos, como filmes, telenovelas, seriados televisivos, trechos de apresentações musicais, videoclipes originais, dentre outros. Como analisam Amaral, Souza e Monteiro (2015, p.8), as produções em fanvideo, no geral, "são caracterizados por

\footnotetext{
12 Tais exemplos, que se configuram como vídeos virais, mas não vídeomemes, posto que não originaram variabilidades, servem para introduzir a nossa reflexão sobre a estética de sua miscelânea. Disponíveis em: 〈https://goo.gl/lla8Sh>; 〈https://goo.gl/TrUJe0>; 〈https://goo.gl/zssSpD>; 〈https://goo.gl/8shfP7>. Acesso em: 05 ago. 2018.
} 


\section{midiäticale}

trilhas sonoras marcantes, inserção de imagens e outros vídeos não relacionados ao original, geralmente, romantizando ou parodiando o conteúdo".

\section{High By The Beach: analisando os videomemes do single da cantora Lana Del Rey}

O videoclipe da música High By The Beach, da cantora de indie pop Lana Del Rey, foi lançado em 13 de agosto de 2015 em seu canal do Vevo no YouTube. A estética simplista da obra empresta certa melancolia onírica da letra da canção, que traduz o desejo da artista de relaxar, ficando "chapada" de narcóticos (marcado pelo stay high, em inglês, no refrão) na praia sozinha, após o fim de um relacionamento problemático que a estava fazendo mal. Em oposição a essa narrativa, o vídeo traz Lana sozinha em uma casa de segundo andar à beira-mar de Malibu, sendo assediada por um helicóptero paparazzi enquanto busca espairecer em sua varanda.

Na reação, a artista decide pôr fim à invasão e começa a correr pelos ambientes da casa em um plano-sequência, dirigindo-se à parte exterior do imóvel e descendo as escadarias com pressa. Entre as pedras da praia, ela busca uma case de violão, de dentro da qual retira uma grande arma de fogo enferrujada, ao que desencadeia sua reviravolta e explode o helicóptero. Há uma clara referência à frequente perseguição sofrida por ela e outros artistas da indústria do entretenimento.

A partir do mesmo dia de lançamento, puderam ser observadas apropriações diversas, tanto apropriando-se como matéria-prima da própria imagem do videoclipe, utilizando-se do plot twist em que Lana desce em correria as escadas para conceder o desfecho merecido aos seus perseguidores, narrativa usada pelos interagentes em variados contextos.

Uma das produções se apropria das cenas e substitui o som por um áudio que brinca com a situação típica de cidades interioranas ou bairros periféricos, nas quais é comum um carro de pamonha percorrer lentamente as ruas com seus alto-falantes bradando: "Olha aí, olha aí freguesia, são as deliciosas pamonhas...", oferecendo a iguaria à sua clientela. A montagem apreende uma situação cotidiana típica em algumas cidades brasileiras ao comportamento de correria de Lana, demonstrando uma vinculação da interpretação do produto midiático a trechos da identidade popular. 


\section{midiätica@e}

Outra produção ${ }^{13}$, de lógica similar, mostra a cantora no clipe descendo as escadas com o áudio original do vídeo substituído pela voz do apresentador Gugu Liberato no quadro Gugu Na Minha Casa, de seu programa Domingo Legal. Nele, telespectadores que haviam enviado cartas o recebiam em sua casa e ganhavam um prêmio em dinheiro a cada item surpresa que Gugu os convocava a localizar na residência, de modo aleatório. Tal diálogo pode ser reconhecido e associado pelo imaginário coletivo a um programa popular, portanto, uma referência familiar para grande parte do público.

Uma terceira pode ser enquadrada como um metameme (INOCÊNCIO, 2016), em que este meme de High By The Beach se apropria de outro há pouco espalhado, o meme "Senhora"14, em que Lana figuraria a servidora da Assembleia Legislativa de Goiás que, ao ser interpelada por uma repórter da filiada Rede Globo local, que a flagrou assinando o ponto na casa e logo após evadindo-se do trabalho deliberadamente, durante uma reportagem que denunciava o funcionarismo público fantasma, inicia uma corrida para não responder às questões da jornalista, que continua a perseguição com o clássico bordão "Senhora, volta aqui, senhora".

Esse compartilhamento de um repertório comum relacionado à possibilidade de expressão criativa de modo coletivo, mesmo que esta seja voltada para uma cômica depreciação de um momento infeliz pelo qual determinada pessoa passou ou uma música mais melancólica, como é o caso de High By The Beach, estimula o intercâmbio de experiências vivenciadas em comum no consumo dos produtos culturais.

Outras versões mostram ainda Lana correndo ${ }^{15}$ para não se atrasar para o Enem, cena clássica frequentemente ironizada nas redes a partir de diversos vídeos de jovens correndo atrasados para realizar o exame; ao som da vinheta do Plantão da Globo ${ }^{16}$; contextualizando a situação em que o carteiro chega com a encomenda da internet;

\footnotetext{
${ }^{13}$ Vídeo disponível em: <https://goo.gl/myMXhK〉. Acesso em: 05 ago. 2018.

${ }^{14}$ Disponível em: <https://goo.gl/381vxJ>. Acesso em: 05 ago. 2018.

${ }^{15}$ Vídeo disponível em: 〈https://goo.gl/RKvXF6>. Acesso em: 05 ago. 2018.

${ }^{16}$ Vídeo disponível em: 〈https://goo.gl/MRgu3k〉. Acesso em: 05 ago. 2018.
} 


\section{midiäticale}

correndo para comprar picolé ${ }^{17}$; além de variados GIFs ressignificando a situação da corrida que não enquadram a matriz linguística - vídeo - que cabe a esta análise.

O tipo de montagem do meme de Lana mais popular, no entanto, é o que suprime o áudio original da canção e embute variadas músicas, como a da funkeira MC Carol, focando na cena em que a cantora Lana Del Rey está na varanda da casa e mira o helicóptero que estaria voyeurizando sua privacidade, ao som da música "Ô Jorginho, me empresta a 'doze', vou matar esse maconheiro", canção que se refere à arma de fogo espingarda de calibre 12 .

Uma das montagens localizadas com o maior número de visualizações também traz o single indie no contexto de outro gênero musical brasileiro. $\mathrm{O}$ vídeo constitui-se da música High By The Beach como trilha de background às imagens de sete jovens dançando a música "Nara do Amor"18 na laje de uma comunidade periférica em Pernambuco, um meme já popular nas comunidades brasileiras, em que se sobrepõe o vídeo da coreografia às variadas trilhas sonoras que vão do gospel ao sertanejo e trash metal.

Encontramos neste objeto, assim, traços do que Soares e Janotti Jr. (2007) chamam de refrões visuais, "marcações visuais que acentuam o estreitamento e a projeção da imagética do clipe em direção a seu espectador" (SOARES; JANOTTI JR., 2007, p.97). Os autores pontuam que, em videoclipes musicais, tais marcações são por vezes coincidentes com o momento do clímax (narrativo ou ritmado) da canção, o refrão, instância em que a retórica sonora se direciona de modo mais pronunciado ao seu destinatário. Essa noção é importante, posto que muitos dos vídeos meméticos que tratamos aqui se ancoram na potência exercida por determinado refrão, cena ou mesmo conjuntos de cenas nos produtos que parodia.

Fundamental para o debate que se desdobra nesta investigação, a noção de cenas musicais, suas disputas, valores e agendamentos é essencial para flexionarmos os videomemes de indie e funk. Nos debruçamos, assim, sobre as proposições de Straw (2013), que observa as cenas musicais enquanto efêmeras assinaturas de territorialidades que postulam um pertencimento comum, assim como a expulsão dos

\footnotetext{
${ }^{17}$ Vídeo disponível em: 〈https://goo.gl/EuQxkD>. Acesso em: 05 ago. 2018.

18 A postagem do vídeo original foi realizada no Facebook e recentemente apagada ao curso da elaboração deste artigo, mas localizou-se o registro do vídeo na plataforma do YouTube. Disponível em: <https://goo.gl/X4yr7B>. Acesso em: 05 ago. 2018.
} 


\title{
midiäticales
}

agentes outsiders, que não reconhecem tais escrituras. As cenas musicais surgiriam, assim a partir dos excessos de sociabilidade que circundam a comunhão de interesses e identificações, fomentando a inovação e a experimentação contínuas no urgir dos modos de vida urbanos. Janotti Jr. (2014) corrobora e indica que ao interpelarmos cenas como uma forma de corporificar a música em suas personificações, pode-se afirmar que estas erguem-se das performatividades inscritas nas encenações, urdindo rastros a partir de performances de gosto, materializando, assim, a chamada música popular massiva.

\begin{abstract}
As cenas musicais são "enquadramentos sensíveis" que permitem, através de disputas e negociações, afirmar territórios sonoros, ou seja, circunscrições de experiências e consumos culturais, articulados por sonoridades e pelo modo como elas circulam, são embaladas e posicionam os participantes das cenas em diferentes circuitos culturais. Já é possível antever nessa descrição a importância das cenas nos processos de identificação cultural com sonoridades e experiências musicais (JANOTTI JR, 2014, p. 2).
\end{abstract}

Para Hennion (2005), trata-se de restaurar a natureza performativa da atividade de gosto atrelado à determinado gênero e, por consequência, sua cena, no lugar de apenas tratá-la como uma constatação. Logo, quando um espectador afirma gostar de ópera ou rock, já está embutido em tal fala que possivelmente ele não gostaria do outro gênero contrário e vice-versa. Assim, como pontua Janotti Jr. (2014 apud HENNION, 2005), ser roqueiro não seria apenas um sentido predileções musicais, mas também suas possibilidades de transitar culturalmente por meio destas performatividades.

\section{Considerações finais}

Ao problematizar algumas questões trazidas para análise, atravessadas por noções como ativismo de fãs, produção colaborativa e performances de gosto, as amostras trazidas parecem referenciar no videoclipe de High By The Beach uma curiosa e inesperada incoerência narrativa, presentificada na correria de Lana Del Rey escadas abaixo. Assim, os fãs-interagentes se apropriaram da produção e, através da edição gráfica em softwares, realizaram uma justaposição associando esta imagem e áudio a outros, que unidas, estabelecem uma relação de sentido ao contexto geral da narrativa.

Casos como esse parecem convidar as respostas meméticas: uma vez que as cenas mostradas nos trechos do videoclipe apresentam alguma incongruência, parecem 


\section{midiäticale}

estar fora de contexto ou em contexto inusitado - Lana correndo a descer as escadas repentinamente - a sua reapropriação para outras situações parece bastante espontânea entre os interagentes, que apresentam estas justaposições para diminuir a incongruência da produção original e reposicionar a personagem em um contexto mais apropriado.

No encadeamento complexo dos exemplos citados, lembramos que tais gêneros musicais brasileiros atravessados por tais produções, como o funk, fazem parte da própria música pop nacional - uma pontuação problemática que, por si só, nos fortalecerá com futuros debates em outros trabalhos, sobre esse pop brasileiro e o britânico, por exemplo. Ao acionar tais sons, populares, periféricos, com ritmos, coreografias e letras carregados da espontaneidade "escrachada" brasileira, se legitima o nacional ao mesmo tempo em que se confronta a qualidade de tal gênero em oposição ao culto indie rock, com sua carga "hipsterizada", atravessando, portanto, diferentes valores, cenas e agendamentos.

A sátira nestes videomemes musicais, assim, se incorpora ao imaginário coletivo em torno dessas situações, constituindo uma produção colaborativa tecida nos moldes da resistência criativa do ativismo de fãs (AMARAL; SOUZA; MONTEIRO, 2015), que em certa medida auxilia na assimilação de determinados acontecimentos por parte dos participantes das redes digitais, ao passo em que os conduz à construção de narrativas participativas de reinterpretação do consumo de bens da indústria do entretenimento. Conforme pontua Jenkins (2009), através de lógicas colaborativas, os interagentes estruturam suas próprias "mitologias pessoais", utilizando como matériaprima a apropriação de trechos do fluxo midiático.

\section{Referências}

AMARAL, Adriana. Subculturas e cibercultura(s): para uma genealogia das identidades de um campo. Revista Famecos, n.37, p.38-44. 2008. Disponível em: <https://goo.gl/fM2qBQ>. Acesso em: 05 ago. 2018.

Manifestações da performatização do gosto nos sites de redes sociais: uma proposta pelo olhar da cultura pop. Revista Ecopós, v. 17, n. 3, 2014. Disponível em: <https://goo.gl/7sBJgB>. Acesso em: 05 ago. 2018.

; SOUZA, Rosa; MONTEIRO, Camila. "De Westeros no \#VemPraRua à shippagem do beijo gay na TV brasileira". Ativismo de fãs: conceitos, resistências e práticas na cultura digital. Revista Galáxia, n. 29, p. 141-154, jun. 2015. 


\section{midiática@e}

BENNET, Lucy Fan activism for social mobilization: A critical review of the literature. Transformative Works and Cultures, v. 10, 2012. Disponível em: <https://goo.gl/Co3zhX>. Acesso em: 05 ago. 2018.

BOURDIEU, Pierre. A Distinção: crítica social do julgamento. Porto Alegre: Zouk, 2007.

BROUGH, Melissa; SHRESTOVA, Sangita. Fandom meets activism: Rethinking civic and political participation. Transformative Works and Cultures. V. 10, 2012. Disponível em: <https://goo.gl/0e9gnN>. Acesso em: ago. 2018.

CAMPANELLI, Vito. Web aesthetics: How Digital Media Affect Culture and Society. Rotterdam: NAi Publishers, 2010.

FISKE, John. Understanding Popular Culture. London: Routledge, 1989.

HENNION, Antoine. Pragmatics of taste. In: JACOBS, M., HANRAHAN, N. The Blackwell Companion to the Sociology of Culture, Blackwell, pp.131-144, 2005.

INOCENCIO, Luana. May the memes be with you: uma análise das teorias dos memes digitais. In: Anais do IX Simpósio de Pesquisadores em Cibercultura ABCiber. São Paulo: ABCiber, 2017. Disponível em: <https://goo.gl/fWjcQF>. Acesso em: 05 ago. 2018.

JANOTTI JR., Jeder. Rock me like the devil: a assinatura das cenas musicais e das identidades metálicas. Recife: L.A.M.A., 2014.

JENKINS, Henry. Cultura da convergência: a colisão entre os velhos e novos meios de comunicação. 2. ed. São Paulo: Aleph, 2009.

; FORD, Sam; GREEN, John. Cultura da Conexão: criando valor e significado por meio da mídia propagável. São Paulo: Aleph, 2015.

MANOVICH, Lev. The Language of New Media. Cambridge: The MIT Press, 2001.

MILNER, Ryan. The world made meme: public conversations and participatory media. Cambridge: MIT Press, 2016.

PEREIRA DE SÁ, Simone. The Numa Numa Dance e Gangnam Style: vídeos musicais no YouTube em múltiplas mediações. In: Revista Galáxia, São Paulo, n. 28, p. 159172, dez. 2014.

SANTAELLA, Lúcia. A estética das linguagens líquidas. In: SANTAELLA, Lucia; ARANTES, Priscila (Orgs.). Estéticas tecnológicas: novos modos de sentir. São Paulo: Educ, 2008.

SHIFMAN, Limor. Memes in digital culture. Cambridge: MIT Press, 2013.

SOARES, Thiago; JANOTTI JR, Jeder. O videoclipe como extensão da canção: apontamentos para análise. In: Revista Galáxia, junho, nº 15, pp. 91-108, 2007.

STRAW, Will. Cenas culturais e as consequências imprevistas das políticas públicas. In: PEREIRA DE SÁ, Simone; JANOTTI JR, Jeder (Orgs). Cenas musicais. Guararema: Anadarco, 2013. 